\title{
TOOL OFFSET INFLUENCE ON MECHANICAL AND MICROSTRUCTURE PROPERTIES OF DISSIMILAR AL6082 AND COPPER FRICTION STIR WELDED JOINTS
}

\author{
CHETHAN $D^{1} \&$ K M SATHISH KUMAR ${ }^{2}$ \\ ${ }^{I}$ Assistant Professor, Department of Mechanical Engineering, Sir M Visvesvaraya Institute of Technology, Bengaluru-562157 \\ ${ }^{2}$ Professor \& Head, Department of Mechanical Engineering, BMS Institute of Technology \& Management, Bengaluru-560064
}

\section{ABSTRACT}

This work is to find the role of tool offset on mechanical and microstructural behaviour of Friction Stir welded of AA6082 and pure copperbutt joints. The major factors considered in this study are, tool rotation speed, tool travel speed and tool offset. The dissimilar butt welds are produced using cylindrical taperd pin by keeping the copper plates on advancing side of joint. Tensile and Bending tests are conducted to evaluate the strength of weld joints. Microhardness test is done in transverse direction of welds to evaluate the hardness distribution on weld nugget. Experimental investigation reveals that, at toolrotational speed»of $1000 \mathrm{rpm}$, tool travel speed of $24 \mathrm{~mm} / \mathrm{min}$ and offset of $1 \mathrm{~mm}$ towards aluminium side yields the better Tensile Strength of 121 Mpa, Bending Strength of 24.3 Mpa and Hardness of $100 \mathrm{HV}$ are obtained at the nugget zone. Microstructure reveals that if more quantity of copper particles are present in the aluminium section at the stir zone, that attributes to good mechanical properties.

KEYWORDS: Friction Stir Welding, Aluminium 6082 Alloy, Copper, Tool Offset

Received: Jun 08, 2020; Accepted: Jun 28, 2020; Published: Aug 29, 2020; Paper Id.: IJMPERDJUN2020956

\section{INTRODUCTION}

In Friction Stir Welding (FSW), a rotating tool with cylindrical shoulder and profile pin is plunged into the joint area. Due to heating and stirring at the joint line it softens the material around the pin which gives plastic deformation. The rotating tool travels along the joint line which leaves a welded zone behind, due to movement of the material from advancing side to the retrieving side[1].The FSW technology is considered to be the most suitable metal joining process to weld dissimilar materials due to its less environmental impact, energy efficiency and economical advantages. Its currently used in industries such as aerospace, nuclear, chemical, electronics, electrical etc.[2][3].

\section{LITERATURE REVIEW}

The joining of Aluminium (Al) to Copper $(\mathrm{Cu})$ is a challenging work because of wide differences in properties. These differences may cause many defects in the weld [4]. Moreover, the Al was easily oxidized at higher temperature, and some welding cracks were produced easily in a joint of brazed or fusion welding. Therefore, excellent weld joints of $\mathrm{Al} / \mathrm{Cu}$ was difficult to get with other welding techniques [5].

Several studies were carried out on joining of $\mathrm{Al}$ and $\mathrm{Cu}$ and influence of process parameters on microstructural and mechanical properties. A good metallurgical bonding in between $\mathrm{Al}$ and $\mathrm{Cu}$ results higher tensile and bending strength [6].Studies also shows that impact of tool profile on microstructure and corrosion 
behaviour of AA2219 Al - Cu friction stir weld nuggets. It was witnessed that the wide deformation experienced at the nugget and the developed microstructure strongly influence the hardness and corrosion behavior [7]. Positioning of base materials will have a solid influence on butt joints morphology and configuration. Irregular morphology was found for the joints produced with keeping aluminium towards advancing side, due to the eviction of the aluminium from weld zone. When the rotating speed is increased, it results in creation of mixing regions with increased dimension, homogeneousness and intermetallic mixture. Tool Shoulder diameter will play a major role on the morphology and intermetallic mixture of the welds nugget. The AA 5083-copper joints were shown excellent surface finishing, but highly defective nugget[8].

Studies also reveals that, flaw free joints could be attained when Cu plate was kept at advancing side" and offset of $1 \mathrm{~mm}$ to the $\mathrm{Al}$ side resulting in good tensile properties. Very poor tensile strength results due to the inadequate response between the $\mathrm{Cu}$ and $\mathrm{Al}$ particles when the pin offset is large and/or low rotation speeds [9].

FSW of aluminium and copper are based on both butt and lap joint arrangements in most studies. Al-Cu butt welding joints were less explored than lap joints, so far, very limited studies for this combination have been conducted. In particular, tool offsetting effect on the material flow configuration and the subsequent properties are yet to be examined indepth for $\mathrm{Al}-\mathrm{Cu}$ materials.

Present study, AA6082 to pure copper plates of $4 \mathrm{~mm}$ thick is friction stir welded by using the parameters, constant tool rotation speed of 1000rpm, three different tool traverse speeds $(16,20,24 \mathrm{~mm} / \mathrm{min})$, and tool positioning of 1 mmtowards advancing side, and for same speed and feed rates taking offset on retrieving side. Finally, mechanical and microstructural properties of joints are evaluated.

\section{EXPERIMENTAL PROCEDURE}

FSW is conducted on Vertical Milling Machine with suitable attachments. Aluminium 6082 alloy and pure copper materials of dimensions $100 \mathrm{~mm} \times 50 \mathrm{mmx} 4 \mathrm{~mm}$ (1xbxh) were used in this work. The workpiece dimensions were selected for convenience to suit the fixtures, which were attached to the longitudinally traversing table of the FSW. The work pieces were thoroughly cleaned before they mounted on fixture by different grade emery paper and acetone in order to remove the residues.

A cylindrical taper unthreaded pin made of $\mathrm{HcHcr}$ steel having $5 \mathrm{~mm}$ major diameter and $3 \mathrm{~mm}$ minor diameter and shoulder diameter of $20 \mathrm{~mm}$ is employed by keeping the tool rotational speed constant, varying feed rate and offsetting the tool towards advancing and retrieving side while other parameters were kept constant. In this experimentation work, a butt weld preparation was used and copper plates were kept on Advancing Side(AS) and Aluminium plates were kept on Retrieving Side(RS).

A schematic of the vertical milling machine and tool employed in this study are shown in Figure 1 and Figure 2.The Table 1 shows the specification of Vertical Milling Machine. The Table 2 to Table 4 indicates physical properties and chemical composition of $\mathrm{Al} 6082$ and Pure Copper. The Figure3 shows the welded joints for selected parameters. 


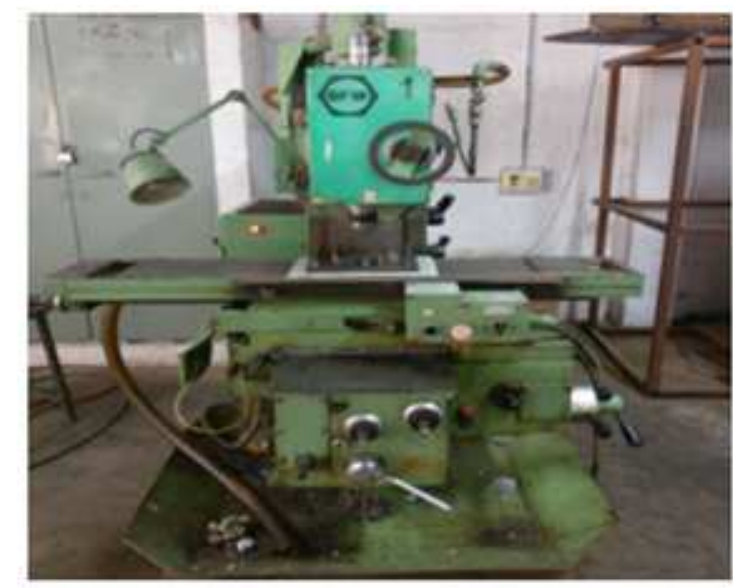

Figure 1: Vertical Milling Machine

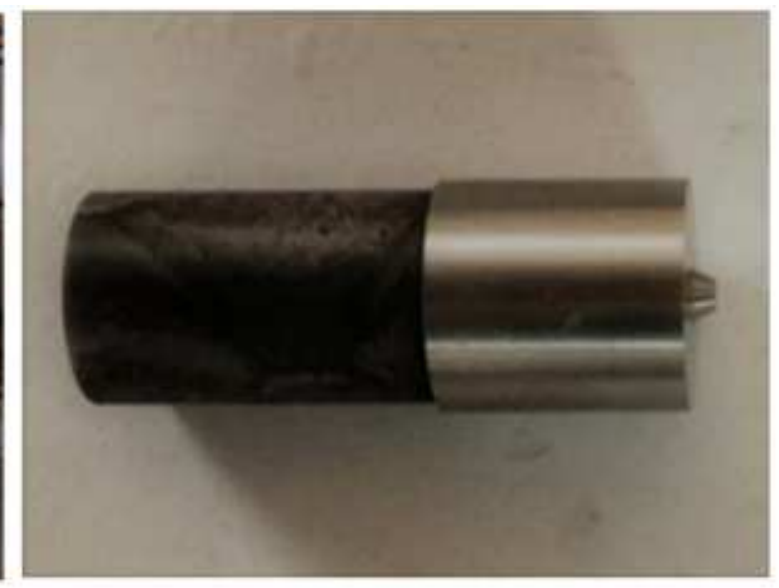

Figure 2: Tool used for FSW process

Table 1: Milling Machine Specification

\begin{tabular}{|l|l|}
\hline Make & BFW \\
\hline Model & UF-1 \\
\hline Table clamping area & $1000 \times 230 \mathrm{~mm}^{2}$ \\
\hline No. of T- slots & 3 \\
\hline Width of T- slots & $14 \mathrm{~mm}$ \\
\hline Centre distance & $45 \mathrm{~mm}$ \\
\hline No. of speeds & $45-2000$ RPM \\
\hline Power of Main motor & $3 \mathrm{HP}$ \\
\hline Motor speed & $1500 \mathrm{rpm}$ \\
\hline
\end{tabular}

Table 2: Physical Properties of Al 6082

Table 3: Physical Properties of Copper

\begin{tabular}{|c|c|}
\hline Density & $2.7 \mathrm{~g} / \mathrm{cm}^{3}$ \\
\hline Melting Point & $555^{\circ} \mathrm{C}$ \\
\hline Modulus of Elasticity & $90 \mathrm{Gpa}$ \\
\hline Poisson's ratio & 0.33 \\
\hline
\end{tabular}

\begin{tabular}{|c|c|}
\hline Density & $8.96 \mathrm{~g} / \mathrm{cm}^{3}$ \\
\hline Melting point & $1083^{\circ} \mathrm{C}$ \\
\hline Modulus of Elasticity & $113 \mathrm{Gpa}$ \\
\hline Poisson's ratio & 0.35 \\
\hline
\end{tabular}

Table 4: Chemical Composition of Al 6082 and Copper

\begin{tabular}{|c|c|c|c|c|c|c|c|c|}
\hline & Si & Cu & Mg & Cr & Fe & Mn & Zn & Al \\
\hline Al 6082 & $0.7-1.3$ & $0-0.1$ & $0.6-1.2$ & 0.25 & $0-0.5$ & $0.4-1$ & $0-0.1$ & Balance \\
\hline $\mathbf{C u}$ & - & 99.99 & - & - & - & - & - & - \\
\hline
\end{tabular}



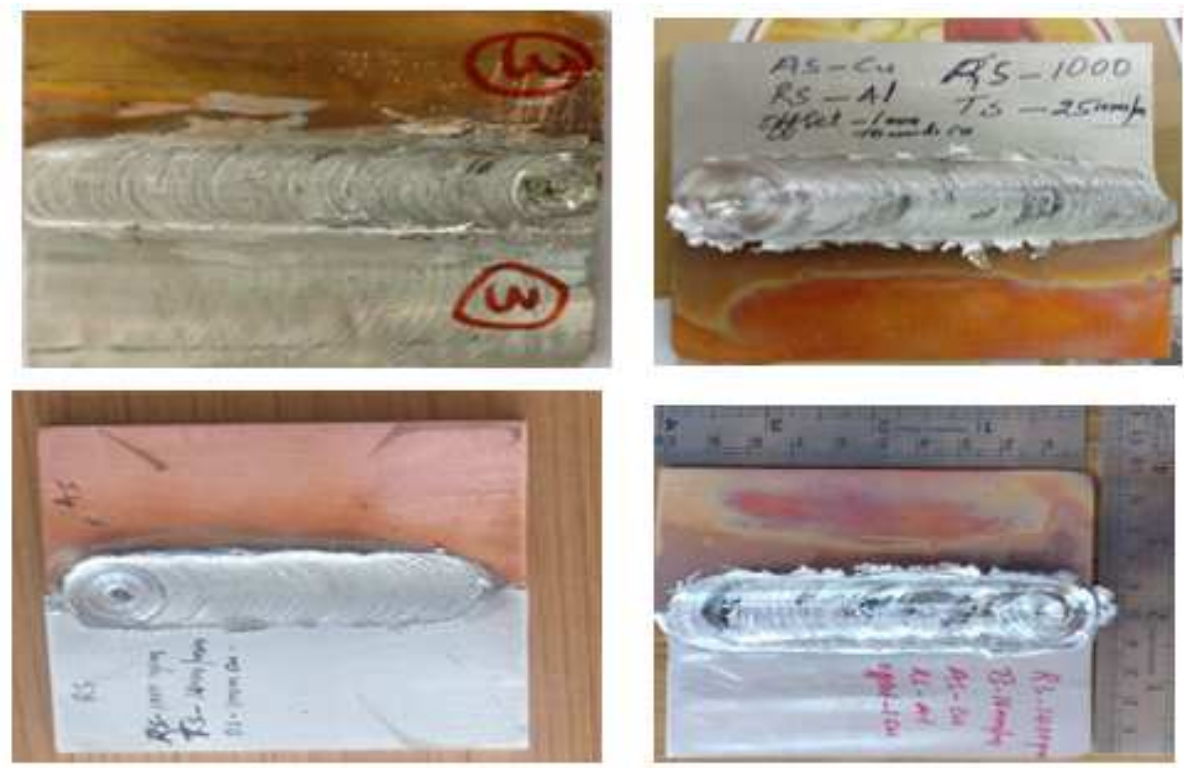

Figure 3: FSW Welded Joints.

\section{RESULTS AND DISCUSSIONS}

\section{Tensile Strength}

To assess the tensile strength of produced joints, the tensile test is conducted. The test samples are prepared with the help of wire EDM based on ASTM standards shown in Figure 4. The obtained results are presented in Table 5.

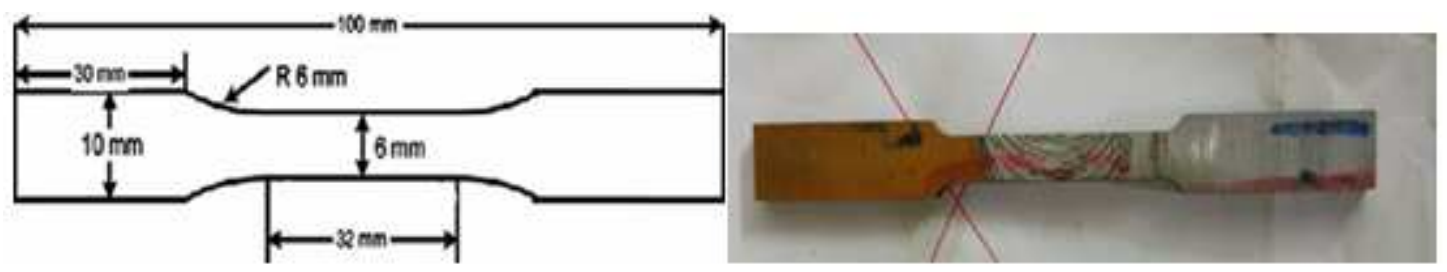

Figure 4: Tensile Specimen as per ASTM Standard.

Table 5: Tensile strength

\begin{tabular}{|c|c|c|c|c|}
\hline Trial No. & $\begin{array}{c}\text { Tool Rotational Speed } \\
(\mathbf{r p m})\end{array}$ & $\begin{array}{c}\text { Tool Travel Speed } \\
(\mathbf{m m} / \mathbf{m i n})\end{array}$ & $\begin{array}{c}\text { Tool offset } \\
(\mathbf{m m})\end{array}$ & $\begin{array}{c}\text { UTS } \\
(\mathbf{M p a})\end{array}$ \\
\hline $\mathbf{l}$ & 1000 & 16 & +1 & 63.8 \\
\hline $\mathbf{2}$ & 1000 & 20 & +1 & 67 \\
\hline $\mathbf{3}$ & 1000 & 24 & +1 & 75.1 \\
\hline $\mathbf{4}$ & 1000 & 16 & -1 & 100.8 \\
\hline $\mathbf{5}$ & 1000 & 20 & -1 & 97.7 \\
\hline $\mathbf{6}$ & 1000 & 24 & -1 & 121 \\
\hline
\end{tabular}




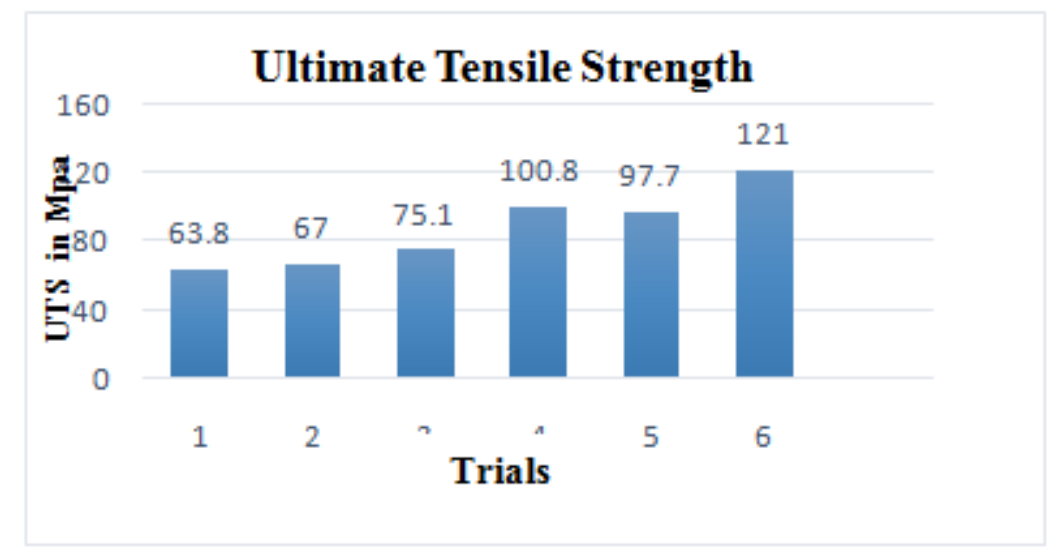

Figure 5: Variation of Tensile Strength.

Figure5 shows the tensile strength of welded joints. It is seen that, the strength of joints increases when the tool is offset towards retrieving side. Maximum tensile strength of $121 \mathrm{MPa}$ is obtained with $24 \mathrm{~mm} / \mathrm{min}$ traverse speed. Though, it is also witnessed that, the tensile strength is reduced for tool traverse speed of $16 \mathrm{~mm} / \mathrm{min}$ and tool offset on advancing side. This is due to lack of creation of any similar mixture at the nugget section and also the inadequate temperature supply at the joint.

\section{Bending Test}

Bend tests are used to understand about the ductility and toughness of welded joints. The "test specimens" are cut as per the ASTM standard for selected thickness as shown in Figure 6.Bending tests are conducted using three point bend test procedure on the test samples cut by wire EDM .The results are tabulated in Table 6.

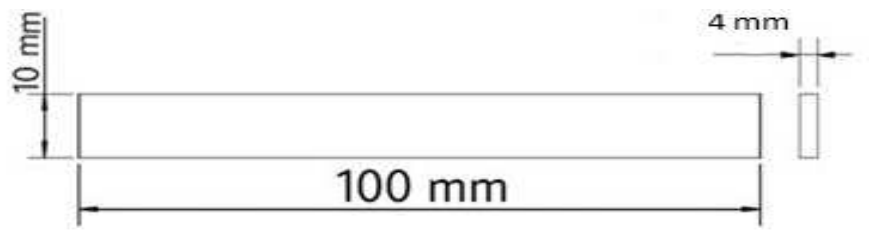

Figure 6: Bending Test Specimen.

Table 6: Bending Stress

\begin{tabular}{|c|c|}
\hline Trial No. & $\begin{array}{c}\text { Bending Stress } \\
\text { (Mpa) }\end{array}$ \\
\hline 1 & 17.3 \\
\hline 2 & 18.4 \\
\hline 3 & 20.8 \\
\hline 4 & 19.5 \\
\hline 5 & 21.1 \\
\hline 6 & 24.3 \\
\hline
\end{tabular}




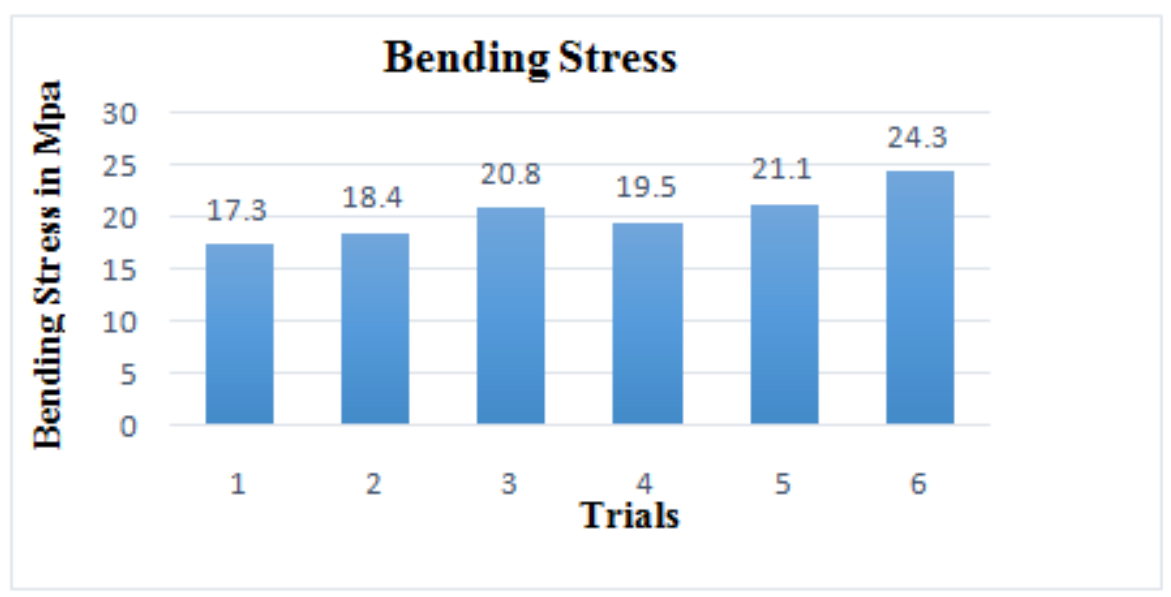

Figure 7: Variation of Bending Stress.

Figure7 shows the bending strength of produced welds. The samples are loaded until U-shape is produced or a failure is caused. Highest bending stress of $24.3 \mathrm{Mpa}$ is obtained for the traverse speed $24 \mathrm{~mm} / \mathrm{min}$ and the tool is offset towards retrieving side. Fractures are found in welded zones and HAZ, especially on the joints that have less tensile strength.

\section{Micro Hardness Test}

To know the strength of FSW joints for various parameters the hardness test may be considered. The Vickers hardness test is conducted on nugget zone of the specimen. Table 7 shows obtained results. Figure 8 shows the variation of hardness on nugget zone.

Table 7: Vickers Hardness Number on Nugget Zone

\begin{tabular}{|c|c|}
\hline Trial no. & Vickers Hardness (Nugget zone) \\
\hline 1 & 66 \\
\hline 2 & 69 \\
\hline 3 & 77 \\
\hline 4 & 95 \\
\hline 5 & 97 \\
\hline 6 & 100 \\
\hline
\end{tabular}

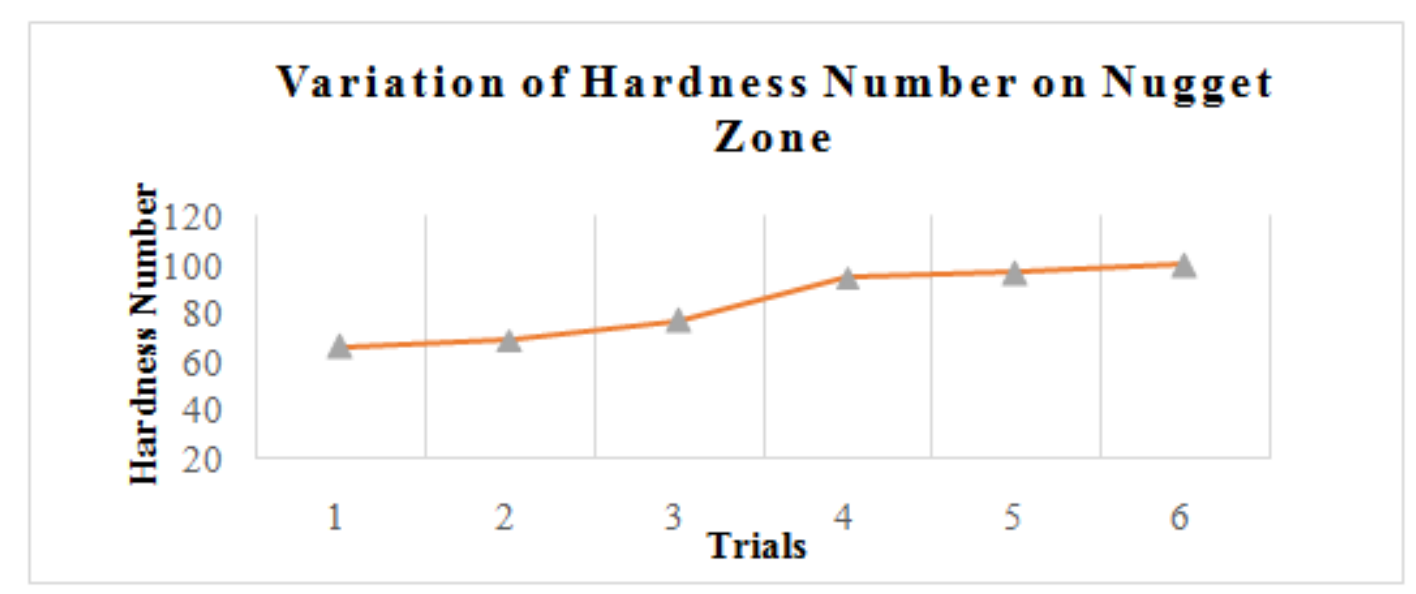

Figure 8: Variation of Hardness Number on Nugget Zone. 
Hardness value of welds in transverse direction are illustrated in the Figure8.It shows that, increase in hardness value at the weld zone is mainly because of intermetallic phases between the $\mathrm{Al}-\mathrm{Cu}$ on the top surface. Highest hardness value of $100 \mathrm{HV}$ is obtained at the nugget zone for transverse speed $24 \mathrm{~mm} / \mathrm{min}$ and tool positioning towards retrieving side.

\section{Microstructure}

Microstructure evaluation is done using "Scanning Electron Microscope (SEM)"with different magnification to know the quality of mixing of materials at nugget zone. Since, it is directly impact on mechanical properties of prepared joints. To understand the amount of material present at weld nugget, results of this test is considered.

In this work, microstructure of weld nugget zone of all the joints are studied. The SEM images and EDS analysis of welded joints are give in Figure 9 to Figure 20

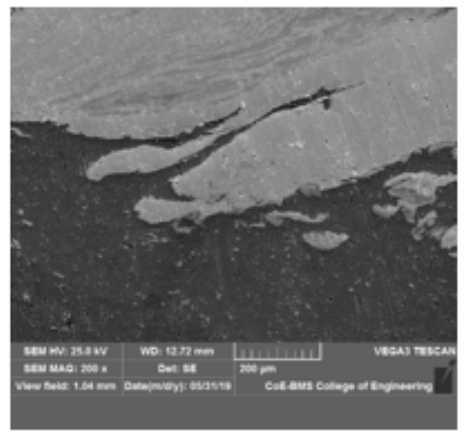

(a) $200 x$

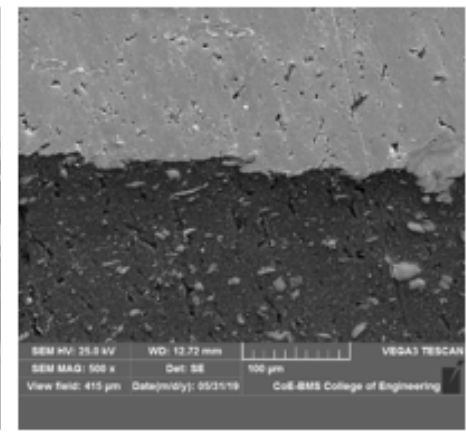

(b) $500 x$

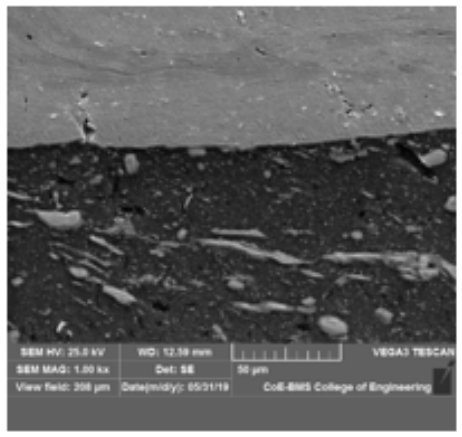

(c) $1000 x$

Figure 9: SEM Images of Trail 1.

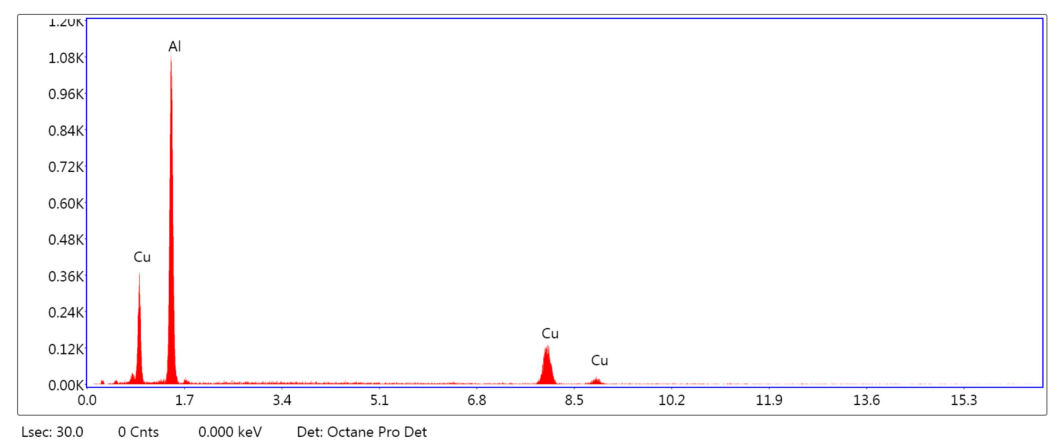

Figure 10: EDS Analysis of Trail 1.

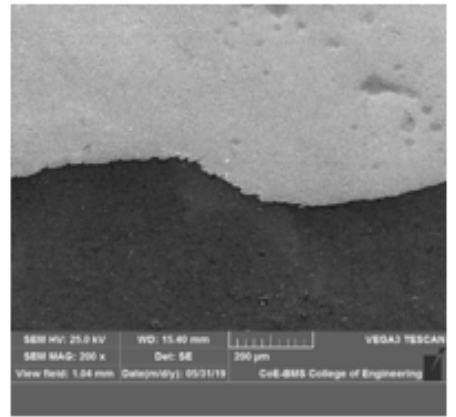

(a) $200 x$

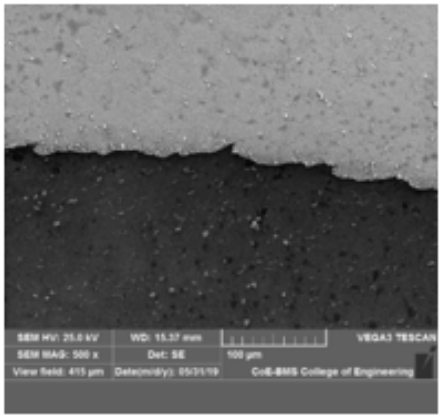

(b) $500 x$

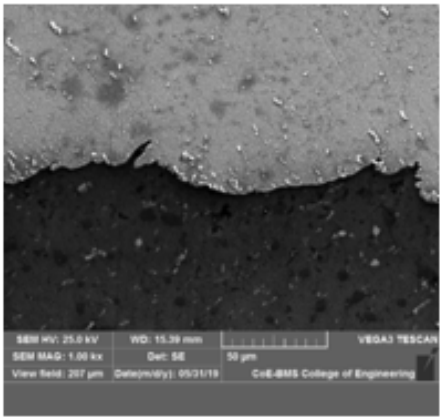

(c) $1000 x$

Figure 11: SEM Images of Trail 2. 


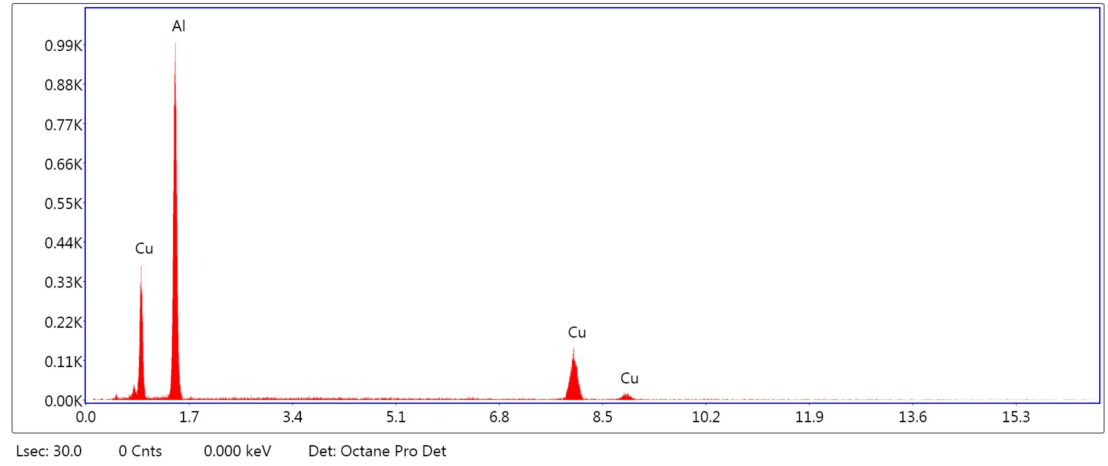

Figure 12: EDS Analysis of Trail 2.

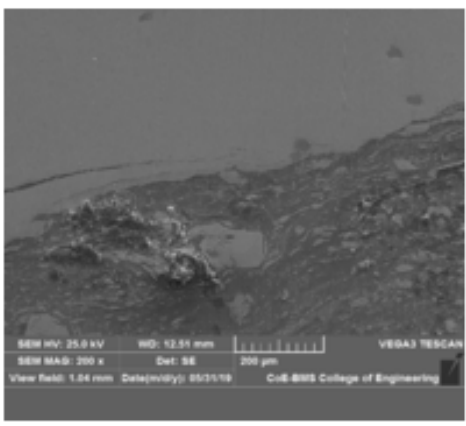

(a) $200 x$

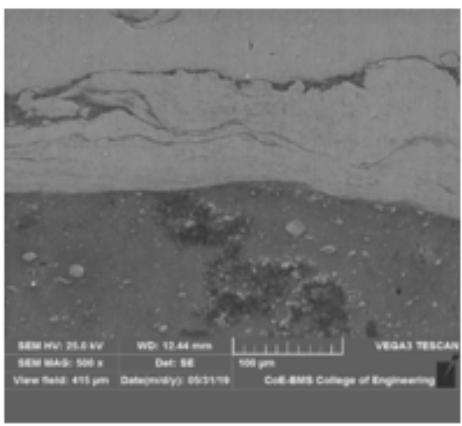

(b) $500 x$

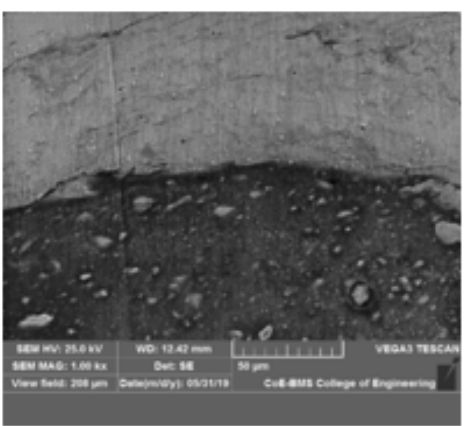

(c) $1000 x$

Figure 13: SEM Images of Trail 3.

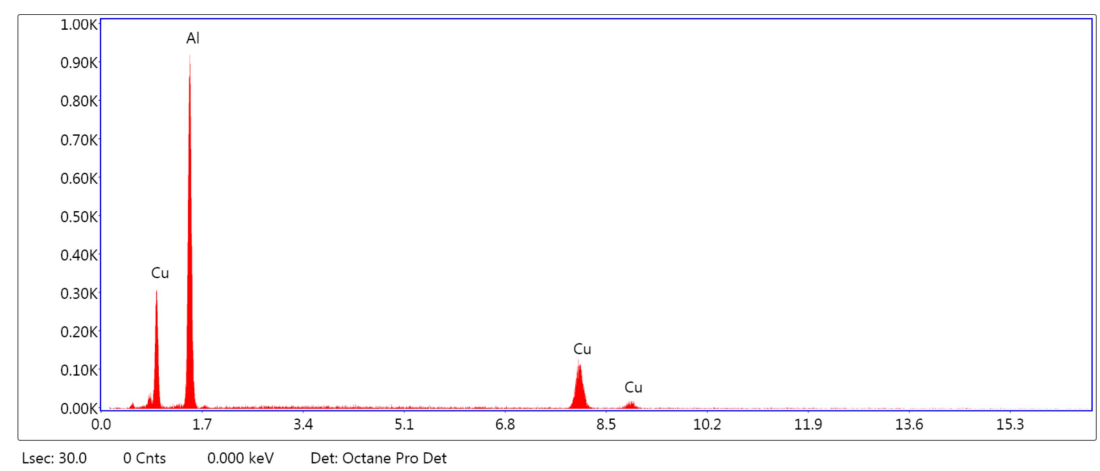

Figure 14: EDS Analysis of Trail 3.

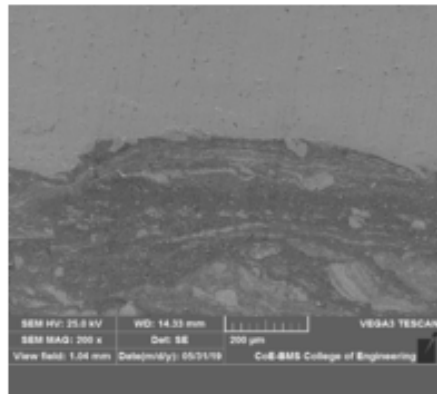

(a) $200 x$

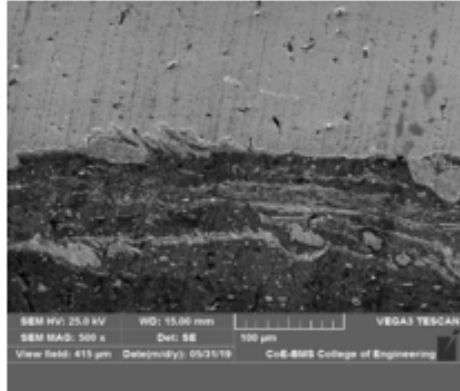

(b) $500 x$

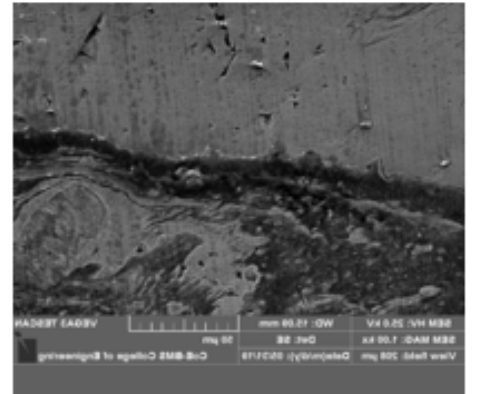

(c) $1000 x$

Figure 15: SEM Images of Trail 4. 

AL6082 and Copper Friction Stir Welded Joints

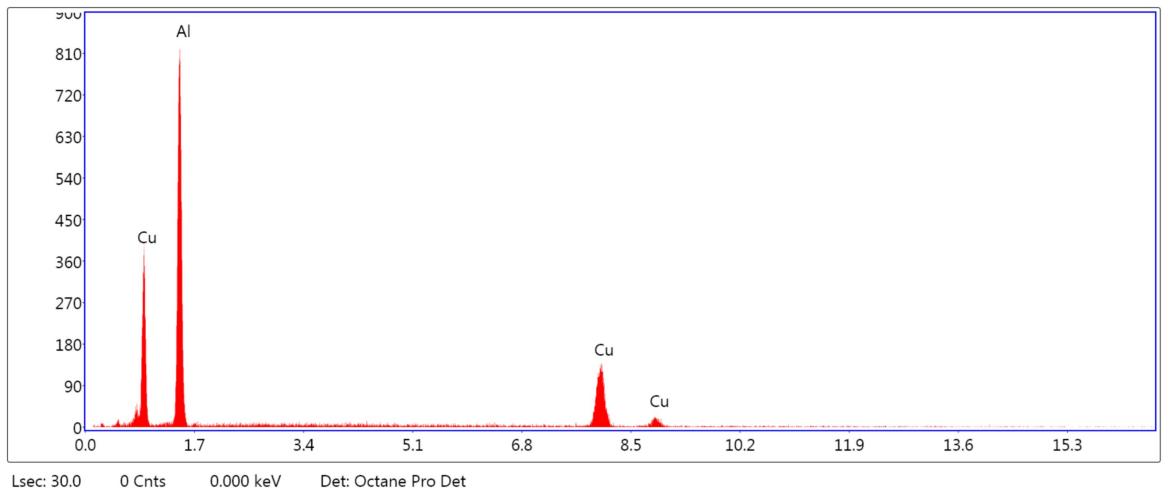

Figure 16: EDS Analysis of Trail 4.

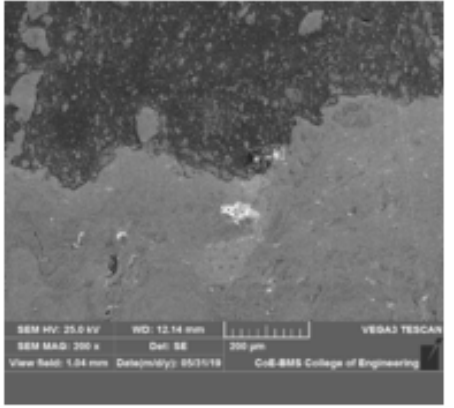

(a) $200 x$

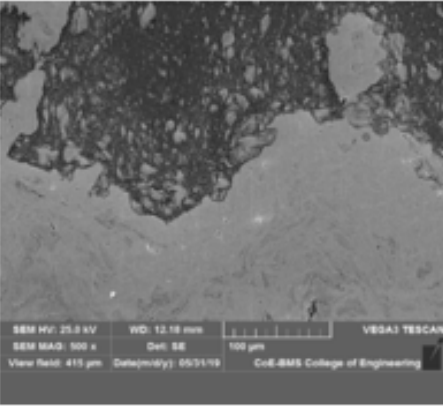

(b) $500 \mathrm{x}$

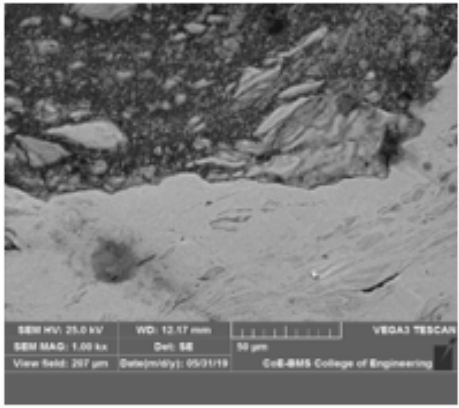

(c) $1000 x$

Figure 17: SEM Images of Trail 5.

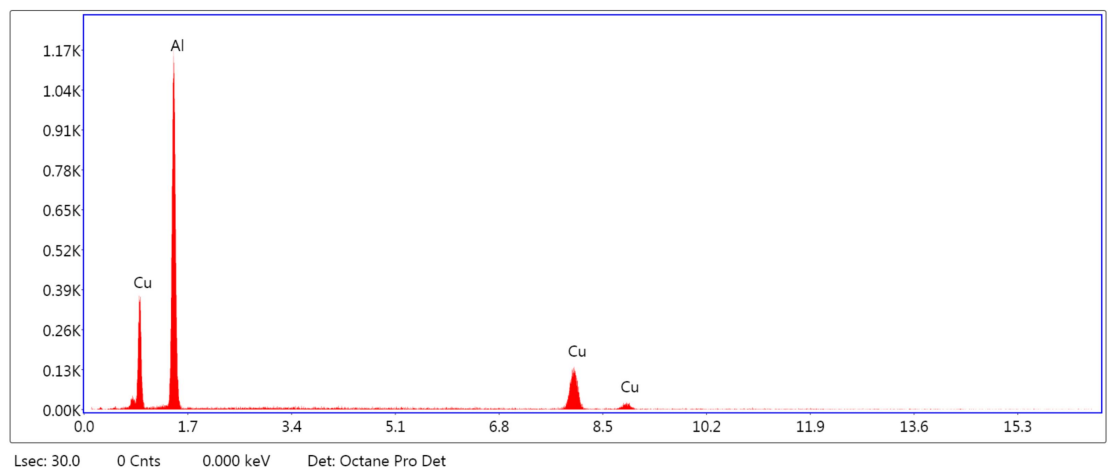

Figure 18: EDS Analysis of Trail 5.

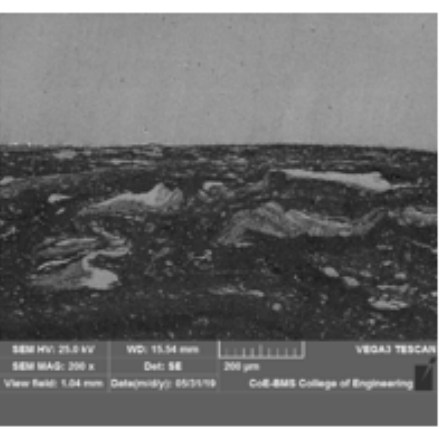

(a) $200 x$

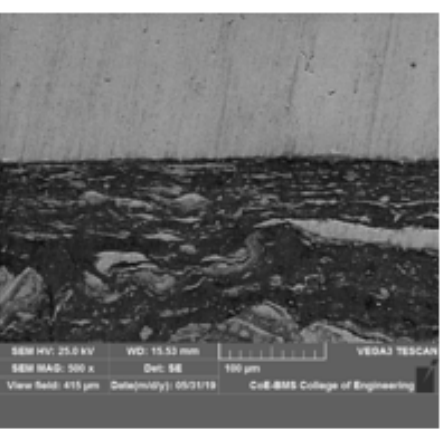

(b) $500 x$

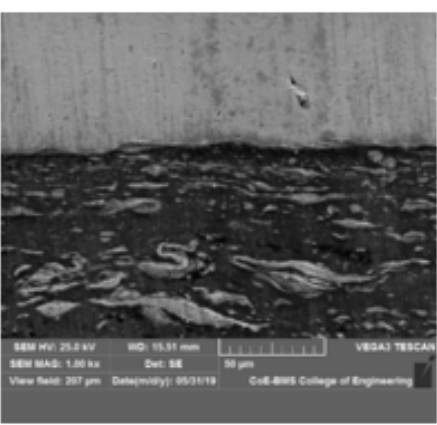

(c) $1000 \mathrm{x}$

Figure 19: SEM Images of Trail 6. 


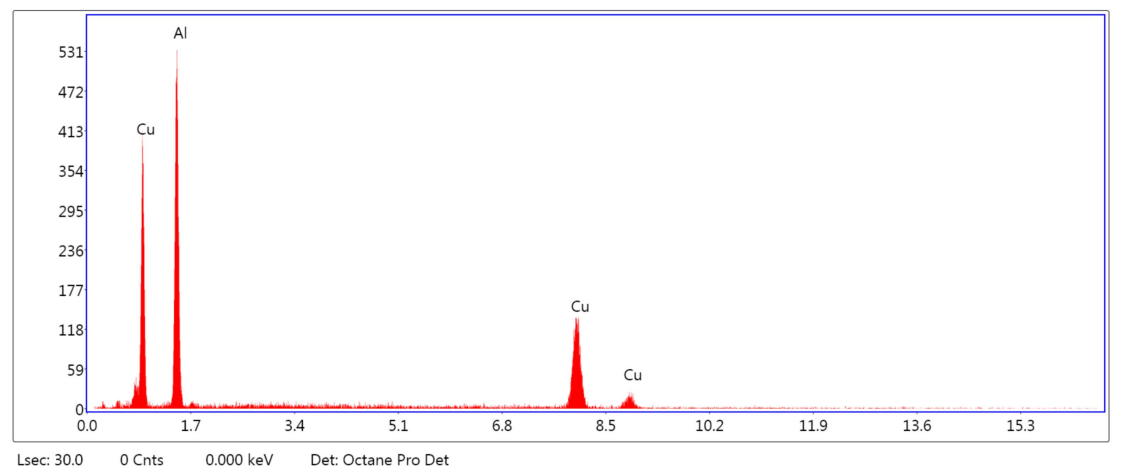

Figure 20: EDS Analysis of Trail 6.

The microstructure images reveals that fine $\mathrm{Cu}$ particles are detached and spread in the nugget zone and also $\mathrm{Al}$ and $\mathrm{Cu}$ matrix interface exists at the nugget zone. It is clear that the uniform distribution of $\mathrm{Cu}$ particlesin $\mathrm{Al}$ results good mechanical properties and non "uniform" distribution of $\mathrm{Cu}$ particles in $\mathrm{Al}$ side results in poor mechanical properties.EDS analysis is also suggest that, if amount of copper at weld nugget is less and if mixing of materials is not sufficient, has a lower strength.

\section{CONCLUSIONS}

The influence of process parameters for Al-Cu FSW joints was analyzed by conducting 6 sets of experiments. The following inferences can be made after the study.

- Joints are successfully produced for the selected parameters.

- $\quad$ Selected material for tool and profile can be used for Al-Cu FSW.

- Experimental investigation reveals that the ultimate tensile and bending strength is maximum1000rpm,24 $\mathrm{mm} / \mathrm{min}$ and offsetting towards retrieving side.

- Maximum hardness is reported for defect-free dissimilar joint for parameter"1000rpm, $24 \mathrm{~mm} / \mathrm{min}$ and offsetting towards retrieving side. Due to presence of intermetallic mixtures in the nugget zone results higher hardness.

- Microstructure and EDS Analysis reveals that for parameter tool "rotational speed" 1000rpm,"tool travel speed24 $\mathrm{mm} / \mathrm{min}$ and offsetting towards retrieving side, more number of copper particles were present in the aluminium section. Higher tensile, bending strength and hardness is credited to the presence of adequate $\mathrm{Cu}$ particles in $\mathrm{Al}$ material at nugget zone.

- Microstructure also reveals that, offsetting of tool towards retrieving side yields the good results. On the other hand, offsetting the tool towards advancing side yields poor results. This is due to improper mingling of $\mathrm{Al}-\mathrm{Cu}$ particles in the weld zone.

\section{REFERENCES}

1. Mukuna Patrick, Mubiayi \& Akinlabi Esther "Friction Stir Welding of Dissimilar Materials between Aluminium Alloys and Copper-An Overview”, Proceedings of the World Congress on Engineering, Vol.3, WCE 2013, July 3 - 5, London, U.K,2013.

2. 1. Rajiv S. Mishra, Z. Y. Mab, Murray W. Mahoney, "Friction Stir Welding and Processing, Materials Science and Engineering”, Reports, 50, USA,2005. 
3. M. Felix Xavier Muthu \& V. Jayabalan, "Tool travel speed effects on the microstructure of friction stir welded aluminumcopper joints", Journal of Materials Processing Technology, Vol.217, pp.105-113,2015.

4. Shaik, Bazani, G. HarinathGowd, and B. Durga Prasad. "An Optimization and Investigation Of Mechanical Properties and Microstructures On Friction Stir Welding Of Aluminium Alloys." International Journal of Mechanical and Production Engineering Research and Development (IJMPERD), ISSN (P): 2249-6890.

5. Kush P. Mehta \& Vishvesh J. Badheka, "Influence of tool design and process parameters on dissimilar friction stir welding of copper to AA6061-T651 joints”, International Journal of Advance Manufacturing Technology, Vol.80, pp.2073-2082,2015.

6. Ahmed O. Al-Roubaiy, Saja M. Nabat \&Andre D. L. Batako, "Experimental and theoretical analysis of friction stir welding of Al-Cu joints”, International Journal of Advance Manufacturing Technology, Vol 71, pp.1631-1642,2014.

7. John, Vivek, et al. "Parametric Analysis and Effect of Tool on FSW Joint of 6082 AL Alloy by Taguchi Method."International Journal of Mechanical and Production Engineering Research and Development (IJMPERD) 8. 1, Feb 2018, 105-110

8. Esther T. Akinlabi, and Stephen A Akinlabi, "Friction Stir Welding of Aluminium and Copper Fracture Surface Characterizations", Proceedings of the World Congress on Engineering, Vol.2,London, U.K,2014.

9. Ch. Venkata rao, G. Madhusudhan reddy \& K. Srinivasa rao, "Influence of tool pin profile on microstructure and corrosion behavior of AA2219 AleCu alloy friction stir weld nuggets", Defence Technology, Vol.11,pp.197-208,2015.

10. Reddy, N. Ravinder, et al. "Optimization of Process Parameters of Friction Stir Welding of AA 6082-T6 Using Grey Based Taguchi Method."International Journal of Mechanical and Production Engineering Research and Development (IJMPERD) 8.1, Feb 2018, 365-372

11. Galvao, I., D. Verdera, D. Gesto, A. Loureiro, and D. M. Rodrigues, "Analysing the challenge of aluminum to copper FSW." Proceedings of 9th International Symposium on Friction Stir Welding, Huntsville, Alabama, US. 2012.

12. Abolusoro, Olatunji P., and Esther T. Akinlabi. "Wear and corrosion behaviour of friction stir welded aluminium alloys-an overview." Int J Mech Prod Eng Res Dev 9 (2019): 967-82.

13. Satyaveer Singh, Dr. Zahid A. Khan, Dr. Arshad Noor Siddiquee "Study on The Effect of FSW Process Parameters On Joint Quality Of Dissimilar Materials", International Journal of Research in Engineering \& Advanced Technology, Volume 3, Issue 2, April-May, 2015, pp.282-298. 

